\title{
Writing and Metacognition: How Italian Students Represent the School Organization and the Assessment Processes
}

\author{
Giovanni Moretti \\ Department of Education, Roma Tre University (Italy) \\ Arianna Giuliani \\ Department of Education, Roma Tre University (Italy) \\ Arianna Lodovica Morini \\ Department of Education, Roma Tre University (Italy)
}

\section{Abstract}

The importance of involving students in writing activities that encourage them to work on metacognitive processes is shared by educational experts (Albanese et al., 2003; Harris et al., 2010; De Simone et al., 2015). During the formative process, activities that require students to use judgment and critical thinking skills, as well as challenging them to reflect on themes close to their daily-life, are those reported to be more effective (Bruning \& Horn, 2000; Boscolo \& Gelati, 2007; Smith et al., 2007). The paper presents the results of a writing laboratory developed with Italian undergraduate students. The students were freshmen at the Department of Education of the Roma Tre University. The main objective was to work on the metacognitive skills of students, asking them to clarify their idea of "school organization and assessment processes in Italy", through a written paper. In addition to argumentative texts, students were asked to identify one or more illustrations to support their own judgment. The research hypothesis was that ideas that students have about scholastic organization and about assessment processes could considerably influence the way in which they approach their academic path. The products of the laboratory were systematically shared and discussed with the students. The result of the research confirms the importance of working with students on writing skills and on metacognition. These are shown to be relevant to the students' educational and professional future.

Keywords: Assessment, Critical thinking, Metacognition, Students, Writing laboratory

\section{Introduction}

The importance of involving students in writing activities that encourage them to work on metacognitive processes is widely believed by experts in the educational field (Albanese et al., 2003; Harris et al., 2010; Boscolo \& Zuin, 2014; De Simone et al., 2015). Writing is one of the basic language skills together with listening, speaking and reading, but not always in teaching practices is specific attention given to strategies that can be effective in promoting its development and/or enhancement (Piemontese and Sposetti, 2014, 2015). It is also made clear in the Recommendation of the European Council on key competences for lifelong learning (2018) that «Individuals should have the skills to communicate both orally and in writing in a variety of communicative situations and to monitor and adapt their own communication to the requirements of the situation. This competence also includes the abilities to distinguish and use different types of texts, to search for, collect and process information, to use aids, and to formulate and express one's oral and written arguments in a convincing way appropriate to the context» (p.5).

In an educational context the act of writing is connected to the ability of a student to elaborate thoughts in an orderly manner and to express their reasoning in a coherent way to fulfill the task that the teacher expects. Requiring students to put their 
writing skills into play in response to tasks in which they are invited to express critical judgments and in which, in a challenging way, they are expected to declare opinions on topics close to everyday life - in particular - is shown by research to be particularly effective (Bruning \& Horn, 2000; Boscolo \& Gelati, 2007; Smith et al., 2007; De Beni et al., 2015).

In a university context, there is sometimes the risk of underestimating the importance of reflecting and working with students on writing, as it is assumed that students have already acquired this ability and are able to use it effectively, flexibly and autonomously. The results of various research projects show that university students demonstrate considerable gaps in competence when producing written texts, including, for example, logical incoherence in expounding the flow of thoughts and the presence of grammatical errors (Stefinlongo, 2002; Sposetti, 2008; Cisotto \& Novello, 2012; Lucisano et al, 2013).

One of the educational devices identified to counter the tendency of underestimating the importance of encouraging the development and enhancement of student writing skills is the laboratory. In particular, those laboratories that encourage students to produce written texts of a certain complexity and which provide forms of feedback referral that allow the student to reflect on and reorganize the written output (Sibilio, 2002; Pietragalla, 2005; Bonaiuti et al., 2016; Hattie, 2016; Giuliani, 2018) are indicated as strategically relevant. In designing laboratory activities of this type, the educational context of the 21 st century can also use digital infrastructure in which to offer meaningful activities to students (Galliani, 2004, Calvani, 2005, Banzato \& Midoro, 2006). In the last decade, for example, many universities have set up training platforms on which to create learning paths in blended or distance-learning modes.

Digital learning environments can be effective in involving students in educational courses that enhance writing skills inasmuch as they offer the possibility, with their own utilities, to provide synchronous and asynchronous communication spaces (chat and forum) where students can engage in informal writing activities. Furthermore, the possibility of preparing areas in which to produce and deliver written work offers the opportunity for students to test their writing skills in a formal educational setting and for teachers to collect useful data to become acquainted with the students and to respond with an assessment judgement also from a distance. To be effective, the teacher's feedback should highlight not only the adequacy or inadequacy of the work as a whole, but should also specifically indicate the reason why the different passages of the written output are correct or wrong. Any errors should be explained to the student in detail so that he/she can refine his/her metacognitive skills and improve his/her performance in subsequent deliveries (Irons, 2007, Shute, 2008, Harks et al., 2014).

A further strategy that can promote the development and enhancement of students' writing skills is peer assessment (Falchikov \& Goldfinch, 2000; Schunk \& Zimmerman, 2012; Lea \& Nicoll, 2013). In fact, involving students in laboratory activities aimed at discussing with their classmates the texts produced and preparing evaluative assessments written to be shared with them can be effective for working on both the assessment and self-assessment capacity of the students and the ability to express judgements in written form. In this context, the teacher should assume the role of observer-mediator, not intervening in the methods implemented by the students except in providing thoughts on revision aimed at increasing student awareness of what they have produced and shared. In this perspective, peer review can be useful not only to develop written communication skills but also to enhance metacognitive skills and to promote student leadership development (Spillane, 2005; Dugan \& Komives, 2007; Moretti \& Giuliani, 2016).

With the intention of working on a cognitive and metacognitive level, in the writing laboratories students should be given tasks asking them to express critical judgment and delivering questions in a semi-structured form (Wiggins, 1998; Domenici, 2005; Tessaro, 2014; Moretti et al, 2015). This type of task seems to be particularly effective because on the one hand it allows students to exercise their writing skills (ability to produce written output, to formulate hypotheses, to solve problems, to re-elaborate texts and to analyze complex situations), and on the other - by inserting limitations in the output, such as limiting the number of lines, the language register, the amount of material to be taken into consideration - it allows the teacher to assess the works in a more objective way. In addition, the teacher, providing feedback to the students on specific 
elements of the text they have written, provides key indications to reflect on in order to improve their performance in future deliveries.

The importance of writing for students should be highlighted both in their personal and education paths and in the future professional path in which they will be protagonists. Knowledge of how to communicate in writing and being able to express critical judgement are among the essential elements for a conscious involvement in active citizenship, and it is therefore important to do research on what may be the most effective strategies to promote their development.

\section{Methodology}

The paper presents the results of a writing laboratory developed with Italian undergraduate students. The students were freshmen at the Department of Education of the Roma Tre University.

The group of students has been identified as attending the course of "Didactic organization and evaluation processes", and therefore involved in the individual and group activities foreseen by the course. The laboratory has foreseen the commitment of the students in individual works that asked to produce written and argumentative texts, followed by a phase of restitution of the results by peers and by the teacher or tutors of the course. The paper deepens the results of one of the laboratory deliveries.

The main objective of the laboratory was to work on the metacognitive skills of students, asking them to clarify their idea of "school organization and assessment processes in Italy", through a written paper. In addition to argumentative texts, students were asked to identify one or more illustrations to support their own judgment and to critically express their own reflection on what they had selected.

The research hypothesis was that ideas that students have about scholastic organization and about assessment processes could considerably influence the way in which they approach their academic path and project into the professional future. As future educators and teachers, in fact, it was considered important to call students' to reflect on their convictions and require them to explain these in a written form. About the text production process, we wanted to investigate how, by asking to develop written answers, individual points of view assumes a linear and structured structure. About the process of sharing the texts, we wanted to investigate how the discussion, the peer evaluation and the self-evaluation can increase students' awareness in supporting and problematizing their opinions. The products of the laboratory were systematically shared and discussed with the students.

The research has been developed through several phases.

During the first phase was implemented an online learning environment in which involve students in laboratory activities. The online environment of the course, accessible on the Department Moodle platform (formonline.uniroma3.it), has been divided into different sections, each one aimed at enhance students as active protagonists of the learning path in different ways. The initial section contains information about teaching, materials for conceptual and methodological study, notices about the course and links to the teacher's personal page. A second section is dedicated to individual and self-assessment activities, and it is here that the activities related to the writing laboratory presented in the paper took place. The last section is dedicated to the development of group work (producing tools and developing projects, but also producing written works). Also this section was aimed at involving students in laboratory activities.

The second phase of the research actively involved students in the writing laboratory. In the forums of the individual activities, several deliveries were introduced; they asked to produce texts in which to express critical judgments on a given topic. The deliveries were articulated with simple language and asked to produce texts of increasing complexity, taking into account the fact that - being freshmen - it was not obvious that everyone mastered adequate skills of writing and expressing critical judgments. The deliveries to be challenging and engaging were formulated in order to investigate issues close to the daily reality or related to the professional future of the students. 
During the third phase of the research, ongoing monitoring activities were carried out on the answers given by the students to the deliveries of the laboratory. The written works were initially evaluated by the teacher and the tutors, and then were encouraged peer evaluation activities in order to give feedbacks. In both cases, a formative evaluative function was promoted, so the approach was constructive and not connected to the allocation of narrowing votes or judgments. The students' writings were systematically presented and discussed and it was interesting to analyse how were activated negotiations and discussions starting from the personal points of view expressed.

In the fourth phase of the research was conducted a final follow-up with the students, in order to reflect collectively about the effectiveness of the laboratory on their cognitive and metacognitive processes. This phase was useful to increase students' awareness about the relevance of the activities in which they were involved a to give to teacher and tutors the opportunity to receive feedback on the quality of the planned formative action.

\section{Main results}

The Department of Education Science platform is a moodle platform in which it is possible to set up a learning environment designed to carry out the activities foreseen in the university courses. The platform has resources to perform both synchronous activities, including chat, and asynchronous activities, including forums and Wiki building. In the course of Didactic Organization and Evaluation Processes the stakeholders active on the platform in addition to the students are the lecturer, author of the course, and the tutors who, in this case, are also experts in the subject. The teacher arranges all the tasks and materials for further study, while the tutors have the role of mediating and accompanying the students in their online learning path. Students can contact the tutors either for technical/IT problems or for explanations on the activities to be performed. In addition, the tutors have the task of stimulating the platform - in particular the forums - to encourage the active participation of all.

The platform has a very friendly user interface that allows students to log on and browse without necessarily possessing advanced technological skills. On the home page of the course, the news Forum where students can find all the up-dated information related to the course and the information given by the lecturer and tutors was highlighted, as well as the link to the teacher's personal bulletin board and the documentation of the course, which collects all the study material and further information on the topics dealt with.

The activities that students are required to perform are divided into individual and group activities. Students are also provided with self-assessment tests that provide personalized feedback based on the answers given. The tests were designed to allow students to monitor their ongoing learning path and check the level achieved in order to make use of additional resources and strategies to bridge any gaps. Figure 1 shows a screenshot of the platform which illustrates the activities related to the course and the individual activities.

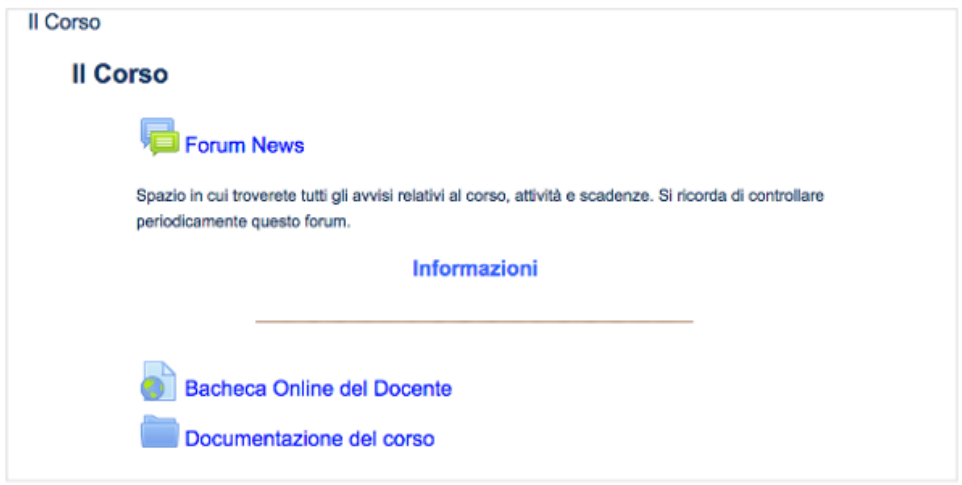




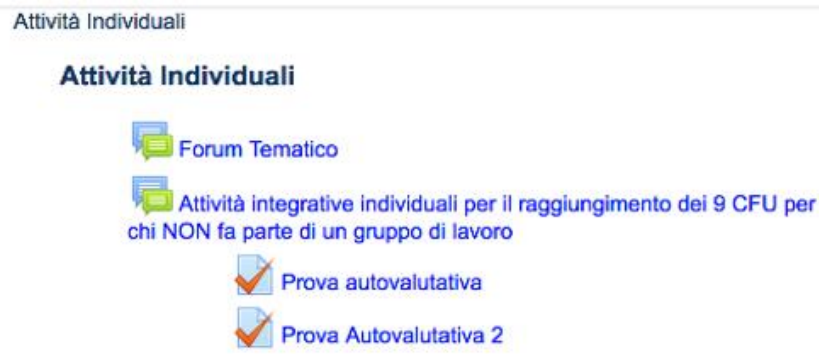

\section{Attività di Gruppo}

Fig. 1: Online platform homepage

This paper presents the results of one of the activities of the individual laboratory. The laboratory was held using a forum in which the following task was proposed: "Choose an image (photo, graphic, etc.) that in your opinion represents an aspect of the scholastic organization or scholastic assessment very widespread in the public imagination. Reply by attaching the file containing the chosen image. Motivate your choice by briefly describing the image and indicating if the represented aspect is to be considered positively or negatively in the prospect of working to raise the quality of the school and learning."

The activity was presented during the progress of the course in question. The course foresees the participation of the students in "blended" mode: partly in the classroom, partly online. The answers of the students were collected by responding to the forum, and during the lessons some of the results were shared in order to open a group discussion, turning the lesson into a dialogue and requiring the active participation of the students.

114 students participated in the workshop. The answers of each one were analyzed in order to verify the structure of the script in terms of the effectiveness of the reasoning, the relevance to the selected image and syntactic and grammatical correctness.

The analysis of the data showed that the students were very motivated to respond to the task. In particular, it was discovered that, following the discussion in the classroom on shared online texts, there was an increase in response on the platform. It is therefore possible to hypothesize that the dissemination of the papers in the classroom prompted the drafting of material by those who had not yet participated. There was therefore no need for a reminder from the lecturer or tutors as the class group seems to have been self-motivated through sharing with other students and experts.

As far as the ability to reason is concerned, it turned out that not only were the majority of students able to effectively discuss the chosen image, but also that they knew how to correctly integrate the issues addressed in the course to support their point of view. The identification of the image has therefore recalled the contents of the course allowing students to put into practice what they learned in theory.

The images identified by the students were found to be representative of the thoughts they wanted to share and were able to effectively illustrate their idea of scholastic organization and assessment. It was interesting to note that, in some cases, the same image was chosen by several students who, however, expressed different observations and points of view. The sharing of their work on the platform did not therefore limit the autonomy of the students who, in the written paper, were able to distinguish themselves by presenting their own opinion in an original way.

From a syntactic and grammatical point of view, the student papers, although in some cases assuming an informal tone, were judged positively. Writing, when proposed in a forum, despite being contextualized in a formal academic environment 
such as a university course, runs the risk of becoming uncontrolled. A good level of writing was found from the analysis of the texts. No scientific or academic writing was required in the task, rather a logical and reasoning approach. In this sense, the construction of sentences was for the most part consistent with the structure. Even grammatical errors were reduced to only a few cases. The forum of the platform does not provide a spell- or grammar checker, so it is clear that the students were concentrating during the drafting of their work.

Below are some texts written by students that can be considered representative of the results obtained in the laboratory.

The first extract brings out the student's ability to reflect through the image he/she has chosen (Figure 2) not only on the main activity that is represented, but also on the environment in which it is performed. During the course, the analysis of the context is afforded significant importance. In this case, the student emphasizes how an ordered environment in which activities are introduced one at a time can be considered strategic to develop in children, starting from early childhood, a sense of order, responsibility and self-sufficiency.

"In this image, it is possible to notice that the children are concentrated in their activities. In my opinion, this kind of activity improves the quality of the kindergarten. The children are able to discover new sensations being in contact with different types of materials, discovering their name, their colours and their shapes. In addition, the surrounding environment is ordered and there aren't other activities going on: this is also very important in order to increase the sense of order, responsibility and autonomy." (C. T. 20 years old)

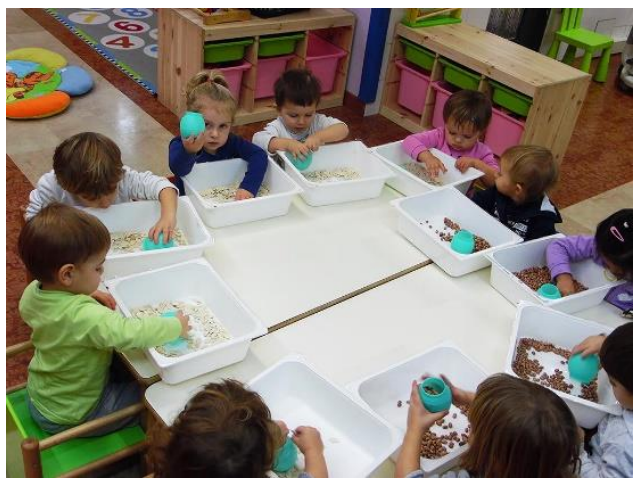

Fig. 2: Manual activities in a kindergarten

With Figure 3, the student wanted to highlight one of the aspects which make it possible to qualify the learning process in the school context, thereby helping to develop some of the key competences. The arrangement of the desks and the sharing of material observed in the image refer to group collaboration activities, indispensable for building learning communities. In this case, the student goes on to report one of the aspects that brings out a positive representation of the school system in which it is possible, through quality initiatives, to achieve the learning goals and develop basic skills to become active citizens. These include responsibility, the ability to collaborate and to develop positive interpersonal relationships.

"I chose this image because, in my opinion, it represents an important aspect of the school organization. In the picture, some children from primary school are cooperating in a group. Working with peers makes the learning activity more engaging and interesting, improving curiosity, interests and responsibility. Within a working group, each child can share his skills and competences, in order to achieve the common purpose. Moreover, this type of activity, in a school environment, avoid competitiveness leaving space for the growing community. Working in a group develop various competences: individual responsibility, interpersonal relationships and cooperative skills. So, it can be considered a positive aspect to raise the quality of school and learning." (F. S. 19 years old) 


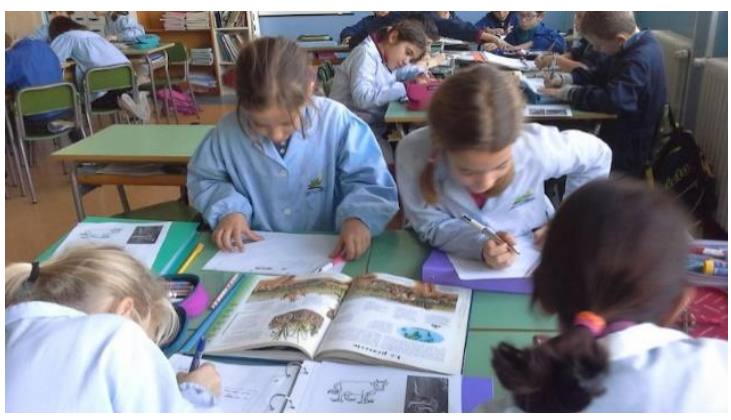

Fig. 4: Group work in a primary school

From the next excerpt emerges the student's ability to contextualize some of the main topics covered in the course: the organization of spaces, the preparation of resources, systematic observation and the importance of making strategic decisions based on the data collected. These themes are effectively discussed by the student, who is able to describe different aspects of the scholastic organization, starting from the photograph represented in Figure 4.

"I chose this photograph representing children involved in drawing and painting activity in an infant school, as I have identified some aspects that I believe are fundamental both for the scholastic organization and for the assessment. In the first place, one can notice a natural aptitude of the environment to carry out this activity, organizing spaces and materials (and therefore resources) to be used. Everything happens thanks to the teacher's observation, which evaluates the strengths and weaknesses of the organization and the success of that single activity, thereby being able to modify during the following activities those aspects that according to her have not been totally functional for the achievement of the objectives (for example it can drive, in one way rather than another, the activity towards sharing). In my opinion this can happen both in structured and routine activities. Nothing is left to chance. The fact of observation and constant assessment is to be considered in my opinion as positively raising the quality of the school "(R.F. 20 years old).

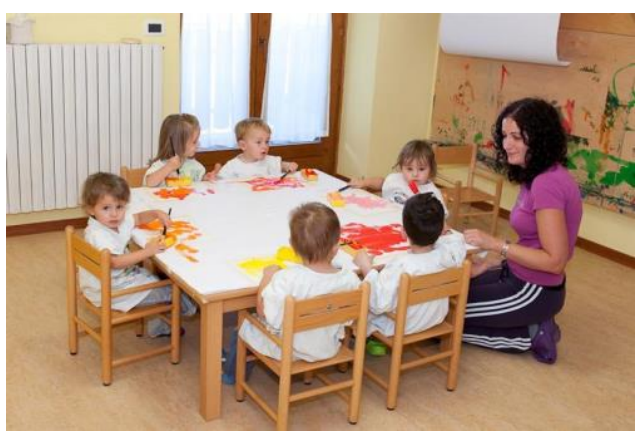

Fig. 4: Drawing and painting activity in an infant school

The following two extracts refer to the topic of assessment. In both cases it becomes evident that in the students' imagination it is one of the critical aspects of the Italian school system. In the first case (Figure 5), the student draws attention to the importance of the emotional aspect linked to the assessment, which is often underestimated by teachers. It has been found in previous research that students at the university are still affected by past assessment experiences, which often threaten a negative influence on educational success (Moretti, Giuliani \& Morini, 2015). The effects of warped judgement, which prejudice objective assessment, are widespread in the scholastic context and those students who are affected find things difficult even at university level. 
"This for me is the first image that comes to mind when the subject of assessment is discussed. This aspect of the educational path is often perceived as negative as it implies a judgement and a significant emotional burden for the child. Overturning this perception, through the involvement of the child in an interactive dynamic exchange with the teacher, would reposition the focus, not so much on the assessment itself, but on the stimulus towards knowledge and further learning in an overall vision of continuous improvement ". (L.P. 20 years old)

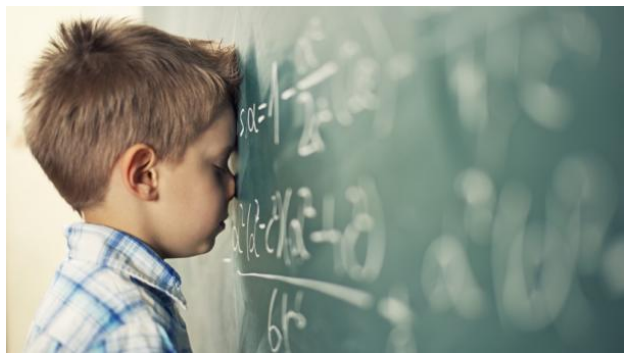

Figure 5: Emotional aspects linked to assessment

In Figure 6, the infamous Sally Brown says in the cartoon "I was judged for what I learnt related to this exercise? If so, weren't you, my teacher, also judged on your ability to share your knowledge with me? Are you willing to share my 5 ? ". The student chose this comic strip to reflect on the assessment function of a judgement expressed by the teacher. The importance of qualifying the teaching element in relation to the learning results of the schoolchildren is emphasized by the student.

"The image I chose refers to the field of scholastic assessment. The significance of the scholastic assessment should be extended to include, in addition to the learning outcomes of the students, the assessment of schooling as one, both at the level of the individual school and of the system as a whole. Not surprisingly, the student of the image I reproduced, asks her teacher to share the "5" she received as an assessment of the set exercise. This is because a fundamental role in student learning is played by the ability and skill of teachers to do their job. The idea of scholastic assessment as a means of promoting the student, but also as a means to improve the overall quality of the school, should therefore become a prevailing concept."(A.R. 19 years old)

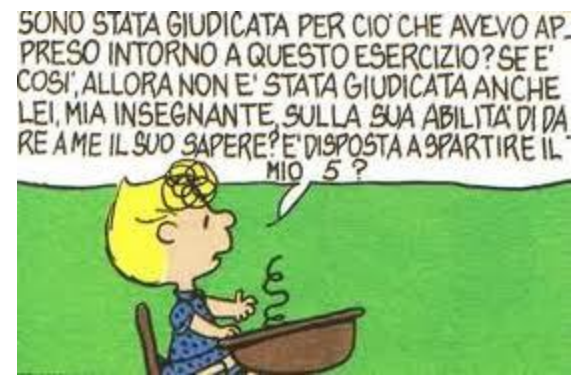

Figure 6: The assessment function in a scholastic context

The texts shown as examples are representative of what emerged from the writing workshop. Students who described aspects of teaching organization have a more positive view on average than students who decided to share their views on assessment. In the students' experience, therefore, a representation of the school emerges that, on the one hand, tries to professionalize the didactic approach by introducing innovative methods, on the other it remains anchored to a traditional assessment structure that sees its limits reflected in the negative experience reported by the schoolchildren. 
In the final phase of the course the students were involved in follow-up activity to reflect on the effectiveness of the laboratory. The data collected in this phase allows for the verification of the planned training programme quality and to further verify the research hypothesis. From what the students have said, the possibility of illustrating their point of view on assessment and scholastic organization in writing, including making use of an image, has resulted in a contribution to develop their cognitive and metacognitive skills. In fact, during the follow-up, students said that the writing laboratory was effective in improving their metacognitive skills.

Some student testimonials collected during this phase are shown below.

"I feel more aware about my formative process. I had the possibility to reflect about Italian schools' practices and about my idea of education. In my paper, I wrote even based my thoughts on my experience in the high school" (G.R., 19 years old).

"I had never attended a writing workshop. I think it was useful both to understand how to write texts effectively and to test our critical spirit on topics that concern us first hand as students" (A.L., 21 years old).

The sharing of reflections by the students was an integral part of the path. The collective discussion has in fact allowed, in addition to gathering feedback, an increase in the students' awareness of the course and of the critical reflections on their opinions and convictions.

\section{Conclusion}

The analysis of the written texts, has allowed us to reflect further on the importance of contributing to develop the metacognitive skills of the students. Through the production of online material the students have been able to deepen their understanding of the didactic organization and the evaluation processes in the Italian context. The possibility of arguing their own point of view using an image or an illustration has made students more aware of their opinions and beliefs. Reflecting individually and sharing in the online learning environment and in presence of their experience is strategic to improve the students' approach in relation to their own training path and their own professional future of educators and teachers.

The results of the research confirm the importance of systematically working both on cognitive and metacognitive skills and on students' writing skills; both these skills are crucial to help ensure training success.

During the follow-up phase, the students expressed their interest in the workshop activities, which allowed them to reflect critically on their experience and on their personal opinions about school organization and evaluation in the Italian context.

Finally, the choice of introducing the "laboratory" as a device into the university course turned out to be effective as it actively involved the students in an activity that requires engagement and critical thinking skills. It is therefore considered important to propose it in a systematic way in the university context activities as well in order to improve writing skills and cognitive and metacognitive skills.

\section{References}

[1] Albanese, O., Doudin, P. A., \& Martin, D. (Eds.). (2003). Metacognizione ed educazione: processi, apprendimenti, strumenti. Milano: FrancoAngeli.

[2] Banzato, M., \& Midoro, V. (2006). Lezioni di tecnologie didattiche. Chieti: Menabò.

[3] Bonaiuti, G., Calvani, A., \& Ranieri, M. (2016). Fondamenti di didattica: teoria e prassi dei dispositivi formativi. Roma: Carocci.

[4] Boscolo, P., \& Gelati, C. (2007). Best practices in promoting motivation for writing. Best practices in writing instruction, 202-221.

[5] Boscolo, P., \& Zuin, E. (a cura di)(2014). Come scrivono gli adolescent. Un'indagine sulla scrittura scolastica e sulla didattica della scrittura. Bologna: II Mulino. 
[6] Bruning, R., \& Horn, C. (2000). Developing motivation to write. Educational psychologist, 35(1), 25-37.

[7] Calvani, A. (2005). Rete, comunità e conoscenza: costruire e gestire dinamiche collaborative. Trento: Erickson.

[8] Cisotto, L, \& Novello, N. (2012). La scrittura di sintesi di studenti del primo anno di Scienze della Formazione Primaria. Giornale Italiano della Ricerca Educativa, 8, 41-57.

[9] De Beni, R., Zamperlin, C., Fabris, M., \& Meneghetti, C. (2015). Studiare meglio e riuscire all'università. Linee guida e materiali per potenziare le abilità di studio. Trento: Erickson.

[10] De Simone, M., Scassillo, S., \& Strollo, M. R. (2015). Metacognizione e scrittura: uno studio pilota di potenziamento metacognitivo nella produzione del testo con alunni di scuola secondaria di primo grado. Ricerche di Pedagogia e Didattica. Journal of Theories and Research in Education, 10(2), 1-38.

[11] Domenici, G. (a cura di) (2005). Le prove semistrutturate di verifica degli apprendimenti. Torino: UTET.

[12] Dugan, J. P., \& Komives, S. R. (2007). Developing leadership capacity in college students. National Clearinghouse for Leadership Programs Retrieved June, 21.

[13] Falchikov, N., \& Goldfinch, J. (2000). Student peer assessment in higher education: A meta-analysis comparing peer and teacher marks. Review of educational research, 70(3), 287-322.

[14] Galliani, L. (2004). La scuola in rete. Roma-Bari: Laterza.

[15] Giuliani, A. (2018). Comunità engaged che apprendono: uno studio sull'efficacia di strategie student-centred nel contesto universitario italiano. In A.M. Notti, G. Moretti \& M.L. Giovannini (a cura di), Quaderni del Dottorato SIRD "La ricerca educativa e didattica nelle scuole di dottorato in Italia" (pp. 119-132). Lecce: Pensa Multimedia.

[16] Harks, B., Rakoczy, K., Hattie, J., Besser, M., \& Klieme, E. (2014). The effects of feedback on achievement, interest and self-evaluation: the role of feedback's perceived usefulness. Educational Psychology, 34(3), 269290.

[17] Harris, K. R., Santangelo, T., \& Graham, S. (2010). Metacognition and strategies instruction in writing. Metacognition, strategy use, and instruction, 226-256.

[18] Hattie, J. (2016). Apprendimento visibile, insegnamento efficace. Trento: Erickson.

[19] Irons, A. (2007). Enhancing learning through formative assessment and feedback. London: Routledge.

[20] Lea, M. R., \& Nicoll, K. (2013). Distributed learning: Social and cultural approaches to practice. Routledge.

[21] Lucisano, P, Brusco, S., Salerni, A., \& Sposetti, P. (2013). Le scritture degli studenti laureati: una analisi delle prove di accesso alla Laurea magistrale in Pedagogia e Scienze dell'educazione e della formazione della "Sapienza". In A. Colombo \& G. Pallotti (eds,), L'italiano per capire (pp.147-165). Roma: Aracne.

[22] Moretti, G., Giuliani, A., \& Morini A. (2015). "Flexible and dialogic instructional strategies and formative feedback: an observational research on the efficacy of assessment practices in italian high schools". ICERI2015 Proceedings, 8229-8236.

[23] Moretti, G., \& Giuliani, A. (2016). "The function of the instructional tools on Students' Distributed Leadership development: an exploratory research in italian academic context". EDULEARN2016 Proceedings, 6187-6195.

[24] Piemontese, M. E., \& Sposetti, P. (a cura di)(2014). La scrittura dalla scuola superiore all'università. Roma: Carocci.

[25] Piemontese, M. E., \& Sposetti, P. (2015). Realizzare un laboratorio di scrittura all'università. Form@ re-Open Journal per la formazione in rete, 15(3), 279-285.

[26] Pietragalla, D. (2005). L'italiano scritto. Manuale di didattica per laboratori di scrittura. Catanzaro: Rubbettino.

[27] Schunk, D. H., \& Zimmerman, B. J. (Eds.). (2012). Motivation and self-regulated learning: Theory, research, and applications. London: Routledge.

[28] Shute, V. J. (2008). Focus on formative feedback. Review of educational research, 78(1), 153-189. 
[29] Sibilio, M. (2002). Il laboratorio come percorso formativo. Napoli: Simone.

[30] Smith, K. S., Rook, J. E., \& Smith, T. W. (2007). Increasing student engagement using effective and metacognitive writing strategies in content areas. Preventing School Failure: Alternative Education for Children and Youth, 51(3), 43-48.

[31] Spillane, J. P. (2005). Distributed leadership. The Educational Forum, 69(2), 143-150.

[32] Sposetti, P. (2008). L'italiano degli studenti universitari. Come parlano e come scrivono. Riflessioni e proposte. Roma: Homolegens.

[33] Stefinlongo, A. (2002). I giovani e la scrittura. Attitudini, bisogni, competenze di scrittura delle nuove generazioni. Roma: Aracne.

[34] Tessaro, F. (2014). Compiti autentici e prove di realtà?. Formazione \& Insegnamento, 12(3), 77-87.

[35] Wiggins, G. P. (1998). Educative assessment: Designing assessments to inform and improve student performance. San Francisco: Jossey-Bass. 